\title{
More homogeneous wind conditions under strong climate change decrease the potential for inter-state balancing of electricity in Europe
}

\author{
Jan Wohland $^{1,2}$, Mark Reyers ${ }^{3}$, Juliane Weber ${ }^{1,2}$, and Dirk Witthaut ${ }^{1,2}$ \\ ${ }^{1}$ Forschungszentrum Jülich, Institute for Energy and Climate Research (IEK-STE), 52428 Jülich, Germany \\ ${ }^{2}$ Institute for Theoretical Physics, University of Cologne, 50937 Cologne, Germany \\ ${ }^{3}$ Institute for Geophysics and Meteorology, University of Cologne, Cologne, Germany
}

Correspondence to: Jan Wohland (j.wohland@fz-juelich.de)

Received: 19 May 2017 - Discussion started: 24 May 2017

Revised: 19 September 2017 - Accepted: 19 October 2017 - Published: 29 November 2017

\begin{abstract}
Limiting anthropogenic climate change requires the fast decarbonization of the electricity system. Renewable electricity generation is determined by the weather and is hence subject to climate change. We simulate the operation of a coarse-scale fully renewable European electricity system based on downscaled highresolution climate data from EURO-CORDEX. Following a high-emission pathway (RCP8.5), we find a robust but modest increase (up to $7 \%$ ) of backup energy in Europe through the end of the 21st century. The absolute increase in the backup energy is almost independent of potential grid expansion, leading to the paradoxical effect that relative impacts of climate change increase in a highly interconnected European system. The increase is rooted in more homogeneous wind conditions over Europe resulting in intensified simultaneous generation

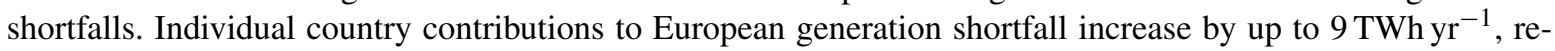
flecting an increase of up to $4 \%$. Our results are strengthened by comparison with a large CMIP5 ensemble using an approach based on circulation weather types.
\end{abstract}

\section{Introduction}

Massive reductions of greenhouse gas emissions are needed in order to reach the temperature goals defined in the Paris Agreement (UNFCCC, 2015; Schleussner et al., 2016b). With a share of around $35 \%$ of current emissions being caused by the electricity system (Bruckner et al., 2014), its decarbonization is the key to any mitigation strategy. However, today's pledges are not yet sufficient to limit warming to below $2{ }^{\circ} \mathrm{C}$, not to mention $1.5^{\circ} \mathrm{C}$ (Rogelj et al., 2016).

In addition to the need of mitigating carbon emissions, a second interaction between the energy system and the climate system exists and becomes increasingly important with higher penetrations of renewable energies. Volatile renewable energy generation is driven by weather conditions which are subject to climate change. Large backup facilities are needed to guarantee a stable supply of electricity during periods of low wind and solar power genera- tion (Rodriguez et al., 2014). Furthermore, climate change affects the demand for electric power (Auffhammer et al., 2017) as well as the operation conditions for thermoelectric and hydroelectric power plants which serve as backup (van Vliet et al., 2016, 2012). However, feedback effects of largescale wind fleets on atmospheric flows are limited (Vautard et al., 2014).

In line with the Paris Agreement, the scientific community is increasingly interested in differentiating climate impacts at 1.5 and $2{ }^{\circ} \mathrm{C}$ (Schleussner et al., 2016a; James et al., 2017) and the IPCC is currently preparing a special report on $1.5^{\circ} \mathrm{C}$. However, many low-carbon pathways rely on negative emissions during the second half of this century (Rogelj et al., 2015; van Vuuren et al., 2016), although their feasibility at scale remains debated (Anderson and Peters, 2016). Future emissions from existing $\mathrm{CO}_{2}$-emitting infrastructure (Davis et al., 2010) and current political developments in the US (Trump, 
2017), among other things, might impede fast decarbonization. Different climatic futures are hence plausible and mitigation strategies need to work in all of them. Therefore, we are led to the question of how sensitive a fully renewable electric power system is to climate change, and, in particular, how severely could strong climate change impact such a system.

Anthropogenic climate change affects the large-scale atmospheric flow and thus the operation conditions for renewable power generation. State-of-the-art global climate models reveal that changes in zonal wind depend on the temperature structure of the lower atmosphere (Haarsma et al., 2013) and that zonal-mean zonal wind and eddy kinetic energy decline almost linearly in time due to polar amplification (Coumou et al., 2015). There are also natural sources of variability at up to decadal timescales. Some of them originate from ocean-atmosphere interactions in the Atlantic and are potentially predictable (Haekkinen et al., 2011; Peings and Magnusdottir, 2014). The North Atlantic Oscillation has been shown to directly influence the operation of interconnected renewable electricity systems (Ely et al., 2013). Predictability of such natural variations is of great interest for system integration and efforts are undertaken to assess and improve forecasting skills (Moemken et al., 2016).

To assess the impact of climate change on the operation of renewable power systems, downscaled climate model output is needed. It comes at a high temporal and spatial resolution and is better suited than global model output to capture local features such as land-sea transitions or mountains (Rummukainen, 2016). Temporal resolutions at the sub-daily scale are needed since electricity consumption varies strongly during the day. Changes in wind energy yields and capacity factors have been assessed based on dynamical (Tobin et al., $2015,2016)$ and statistical-dynamical downscaling outputs (Reyers et al., 2015, 2016). Tobin et al. (2016) evaluate the EURO-CORDEX data archive and find that changes in the annual wind energy yield across Europe are of the order of $5 \%$ and models do not agree on the sign of change. Following a different approach that allows for the inclusion of the output of 22 global climate models, Reyers et al. (2016) report an increasing intra-annual gradient between winter and summer wind generation and different trends in northern and central Europe as compared to southern Europe.

Assessing changes in solar power generation is arguably more difficult due to, among other things, unresolved processes in relatively coarse climate models and uncertain parameterizations (e.g., Chiacchio et al., 2015; Herwehe et al., 2014). Acknowledging this difficulty and associated uncertainties, an evaluation of the EURO-CORDEX data finds limited impacts of climate change on solar photovoltaic (PV) potentials (Jerez et al., 2015). Southern Europe, having the highest potential for PV, sees only small changes, as an increase in downwelling irradiation is counteracted by a decreasing efficiency due to warming. In contrast, the output of concentrated solar power systems (CSPs) is expected to increase by around $10 \%$ because the efficiency of CSP increases with temperature (Crook et al., 2011).

While wind and solar power sources have shown remarkable development in the last decades, system integration remains a huge challenge (Huber et al., 2014). In a highly renewable power system the timing of generation events becomes crucial. Even in an European electricity system that is on average fed by $100 \%$ renewables, roughly one-quarter of the energy is produced at the wrong time and has to be curtailed (Rodriguez et al., 2014, 2015a).

It is thus necessary to consider indicators such as the variability and synchronicity of generation in addition to total energy yields (Monforti et al., 2016; Bruckner et al., 2014; Bloomfield et al., 2016). Several validated time series of renewable generation based on reanalysis data are available to assess the power system operation (Pfenninger and Staffell, 2016; Staffell and Pfenninger, 2016; Gonzalez Aparcio et al., 2016). However, these data sets are restricted to current climatic conditions and might thus be misleading for long-term planning of the electricity system.

In this article we study the impact of climate change on the operation conditions for future fully renewable power systems. We combine the analysis and simulation of power systems with high-resolution regional climate modeling results to quantify changes in wind power generation. We adopt a coarse-scale view on the power system to uncover the largescale impacts of climate change. The coarse-scale perspective neglects details that are irrelevant for the balancing of demand with wind generation such as supply of reactive power or different voltage levels in the grid. The focus of this study is to address the potential of transnational power transmission to cover local balancing needs.

Our results reveal the sensitivity of fully renewable power systems to climate change. They should not be mistaken with a forecast and rather be considered a thought experiment to assess potential risks and to answer the following question: what happens to a fully renewable electricity system if mitigation actions are ineffective or come too late?

\section{Methods}

\section{Modeling the operation of a fully renewable power system under climate change}

To assess the impact of strong climate change, we simulate the operation of a fully renewable power system making use of high-resolution climate projections. We use the EURO-CORDEX ensemble containing output of global circulation models (GCMs) which has been dynamically downscaled to a finer resolution (Jacob et al., 2014) to quantify changes in wind power generation. The ensemble contains five GCMs (HadGEM2-ES, CNRM-CM5, EC-EARTH, CM5A-MR amd MPI-ESM-LR) which are all downscaled by the regional climate model RCA4 (Strandberg et al., 2015). The GCM output is part of the Climate Model In- 
tercomparison Project Phase 5 (CMIP5) and publicly available (Taylor et al., 2011). We use near-surface wind speeds at $0.11^{\circ}$ spatial and $3 \mathrm{~h}$ temporal resolution and hence capture intra-day effects. In the spirit of a sensitivity analysis, we evaluate the representative concentration pathway RCP8.5. It describes atmospheric greenhouse gas concentrations following a business-as-usual strategy and leads to approximately $4.3^{\circ} \mathrm{C}$ warming at the end of the century as compared to pre-industrial values (Stocker et al., 2013). In view of inter-model spread and other uncertainties, a strong climate change scenario bears the advantage of high signal-tonoise ratios.

The approach used in this study is illustrated in Fig. 1. The climate data is used to calculate the aggregated wind power generation time series for each country in the interconnected European power grid (grey circles in Fig. 1a). Near-surface wind speeds are scaled up to hub height $(80 \mathrm{~m})$ based on a power law and a standard power curve is used to obtain the power generation of the wind turbines, both as in Tobin et al. (2016; see also Supplement S1). The power curve assumes a cut-in velocity of $3.5 \mathrm{~m} \mathrm{~s}^{-1}$, a rated velocity of $12 \mathrm{~m} \mathrm{~s}^{-1}$ and a cut-out velocity of $25 \mathrm{~m} \mathrm{~s}^{-1}$. Wake losses are not accounted for. The country-wise aggregated wind power is obtained by summing the generation of $100 \mathrm{MW}$ wind parks until the system is fully renewable on average. The wind park size was chosen as a compromise between increasing turbine capacities (Wiser et al., 2016) and the need for a sufficient amount of distinct parks. Wind parks are deployed semirandomly following the approach of Monforti et al. (2016). In order to single out climate-change-induced alterations, we fix the technological parameters such as hub heights or turbine efficiencies, and we do not account for changes in the consumption such as load shifting or sector coupling throughout the 21st century. Tests including validated historical PV time series (Pfenninger and Staffell, 2016) reveal that the inclusion of PV does not change the overall results (see Supplement S2). For the sake of simplicity, we thus decide to restrict the analysis to wind-driven power systems in this paper.

Wind power generation strongly fluctuates over various timescales as shown in Fig. 1c. In periods of scarcity, energy has to be imported from other countries or generated from local dispatchable power plants. We refer to the latter as backup energy. In the situation depicted in Fig. 1a, scarcity in southern Europe can mainly be compensated for by imports from northern Europe. Transnational balancing of this kind often requires large transmission capacities. Moreover, the import of electric energy requires a respective exporter which has a surplus at the same time. Backup energy in future renewable power systems is thus essentially determined by the temporal and spatial heterogeneity of wind and solar power throughout the system.

In addition to enhanced spatial balancing via imports and exports, an extension of storage facilities will reduce backup energy (Rasmussen et al., 2012). However, storage assets are more costly than grid expansion (Schlachtberger et al., 2017;
Brown et al., 2016). Since a cost-optimal solution will thus favor grid expansion, we focus on spatial effects and transnational balancing. An assessment of climate change effects on storage following a similar approach is presented by Weber et al. (2017).

To quantify backup energy, we adopt a coarse-scale view of the transmission system (see, e.g., Rodriguez et al., 2015a, 2014). We consider each country $i$ to be a node in the European transmission network and define a nodal mismatch for each point in time $t=1,2, \ldots$ as

$M_{i}(t)=P_{i}(t)-D_{i}(t)$

where $P_{i}(t)$ is intermittent renewable generation and $D_{i}(t)$ is the load (here hourly data for 2015 averaged over $3 \mathrm{~h}$ time steps from ENTSO-E; European Network of Transmission System Operators for Electricity, 2015). The assumption of a fully renewable system means that all countries generate as much electricity as needed on average $\left(\int_{t_{s}}^{t_{e}} M_{i}(t) \mathrm{d} t=0\right)$. The assumption of a fully renewable system means that all countries generate as much electricity as needed on average (integral), where $t_{s}$ and $t_{e}$ are defined in Table 1. Furthermore, we assume all countries to run a loss-free and unlimited transmission network within their borders.

If a country has a negative mismatch $\left(M_{i}<0\right.$, red circles in Fig. 1d), it tries to import energy. If it has a positive mismatch $\left(M_{i}>0\right.$, green circles in Fig. 1d), it tries to export energy. For each country $i$ the power balance must be satisfied:

$M_{i}(t)+B_{i}(t)+F_{i}(t)=C_{i}(t)$.

The mismatch $M_{i}$ can be compensated for either by power generation from conventional backup power plants $\left(B_{i} \geq 0\right)$, the curtailment of renewable power generation $\left(C_{i} \geq 0\right)$ or by imports $\left(F_{i}>0\right)$ or exports $\left(F_{i}<0\right)$. To utilize renewable generation in an optimal way, countries will first try to balance power using imports and exports. However, a perfect balancing of all nodes is impossible if there is a continentwise shortage or overproduction. Furthermore, cross-border flows along lines are bound by the directional net transfer capacities (NTCs; see Supplement S1 for details), which may also impede balancing for some nodes. Power balance must then be satisfied by local means: in the case of a shortage, power must be backed up by conventional generators $\left(B_{i}>0\right)$. Similarly, if excess power can not be exported, it has to be curtailed $\left(C_{i}>0\right)$. We recognize that the technical details of backup generation often matter for implementation (Schlachtberger et al., 2016), but we focus on gross electricity needs in this study.

For each time step we determine the system operation which minimizes backup power and thus macroeconomic costs as well as greenhouse gas emissions. To assess the impact of climate change, we compare future backup energy to historical values. Time frames are chosen to contain 20 years in order to capture natural variability of the climate system on 

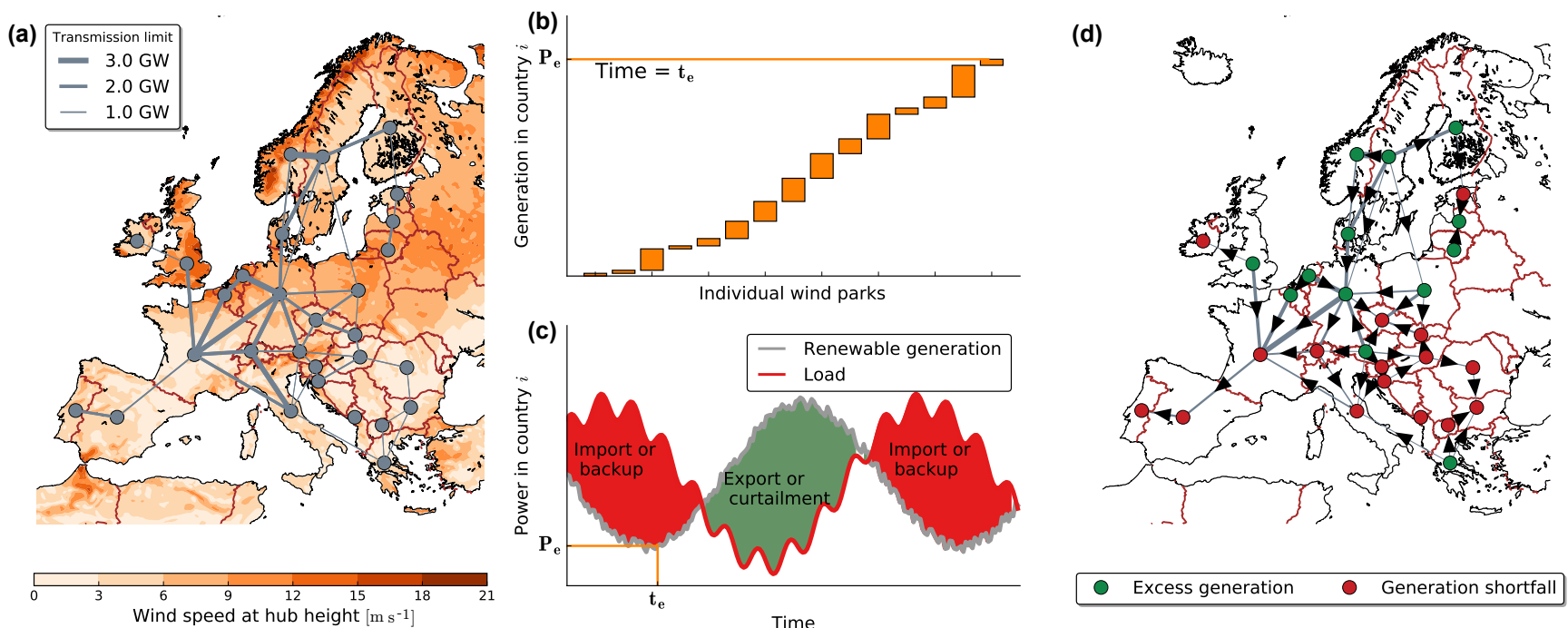

Figure 1. Approach of the study. (a) Wind fields from high-resolution climate models and the 2010/2011 net transfer capacities are used as input to the model. (b) The wind speeds are first translated into generation of individual wind parks using local wind fields and then aggregated to a national level for each country. (c) In combination with country-specific load data, the nodal mismatch for every country and time step is computed. If generation exceeds the load (green area), countries can export energy until lines reach their transmission capacity. Remaining energy has to be curtailed (dumped). If generation is lower than load, electricity will be imported. If importing is not an option due to transmission limits or lack of available excess energy in other countries, backup energy has to be provided by dispatchable power plants. (d) A minimization of the total backup energy of all countries then yields a flow pattern in Europe.

a multi-year timescale while still ensuring that elapsed time between periods is long enough to consider them distinctly (see Table 1). Since GCMs do not reproduce natural variations synchronously (Farneti, 2017), robust signals found in the ensemble are very unlikely to be rooted in natural variations with a recurrence time of a couple of decades (such as the Atlantic Meridional Oscillation or the North Atlantic Oscillation; see Peings and Magnusdottir, 2014, for a discussion of their role in mediating atmospheric conditions). The backup energy $E_{\mathrm{B}}$ per period is defined as the sum over all backup powers in a given period:

$$
E_{\mathrm{B}}(\text { period })=\sum_{t \in \text { period }} \min \sum_{i} B_{i}(t)
$$

such that Eq. (2) is satisfied for all countries $i$ and the line limits are respected.

The European amount of backup energy is identical to the amount of curtailment over a full period. This is a direct consequence of the assumptions made and can be formally derived by summing Eq. (2) over all countries and integrating over an entire period. Since $\int_{t_{s}}^{t_{e}} M_{i}(t) \mathrm{d} t=0$ (each country is fully renewable on average) and $\sum_{i} F_{i}=0$ (all imports to one country $F_{j}=c$ are exports from another $F_{k}=-c$ ), it follows that

$$
\int_{t_{s}}^{t_{e}} \sum_{i} B_{i}(t) \mathrm{d} t=\int_{t_{s}}^{t_{e}} \sum_{i} C_{i}(t) \mathrm{d} t .
$$

A change of the backup energy thus directly implies a change in total curtailment.

We use climate model ensembles to account for model uncertainties. Interpreting the ensemble output by means of the ensemble mean can be misleading as a single model might dominate the ensemble. In such cases, the model mean would be in disarray with the majority of models and hence would not be representative of the ensemble. We thus assess the robustness of changes by means of inter-model agreement. We label a signal "robust" if all models agree on the sign of change and use "high agreement" if all but one model agree. In the evaluation of the large CMIP5 ensemble we adopt language defined for the latest IPCC report and label a change "likely" if at least $66 \%$ of models agree (Mastrandrea et al., 2010).

A variety of studies have analyzed transmission and backup energy in future renewable power systems and costoptimal transition pathways in a similar way (Rodriguez et al., 2015a, 2014, 2015b; Becker et al., 2014; Rasmussen et al., 2012; Schlachtberger et al., 2016; Hagspiel et al., 2014). However, the potentially crucial role of changes in climatic conditions have not yet been assessed in this context. The remainder of this article focuses on the quantification of impacts to the power system, a correlation analysis of wind resources and an assessment of the larger CMIP5 ensemble to contextualize our findings. 
(a)
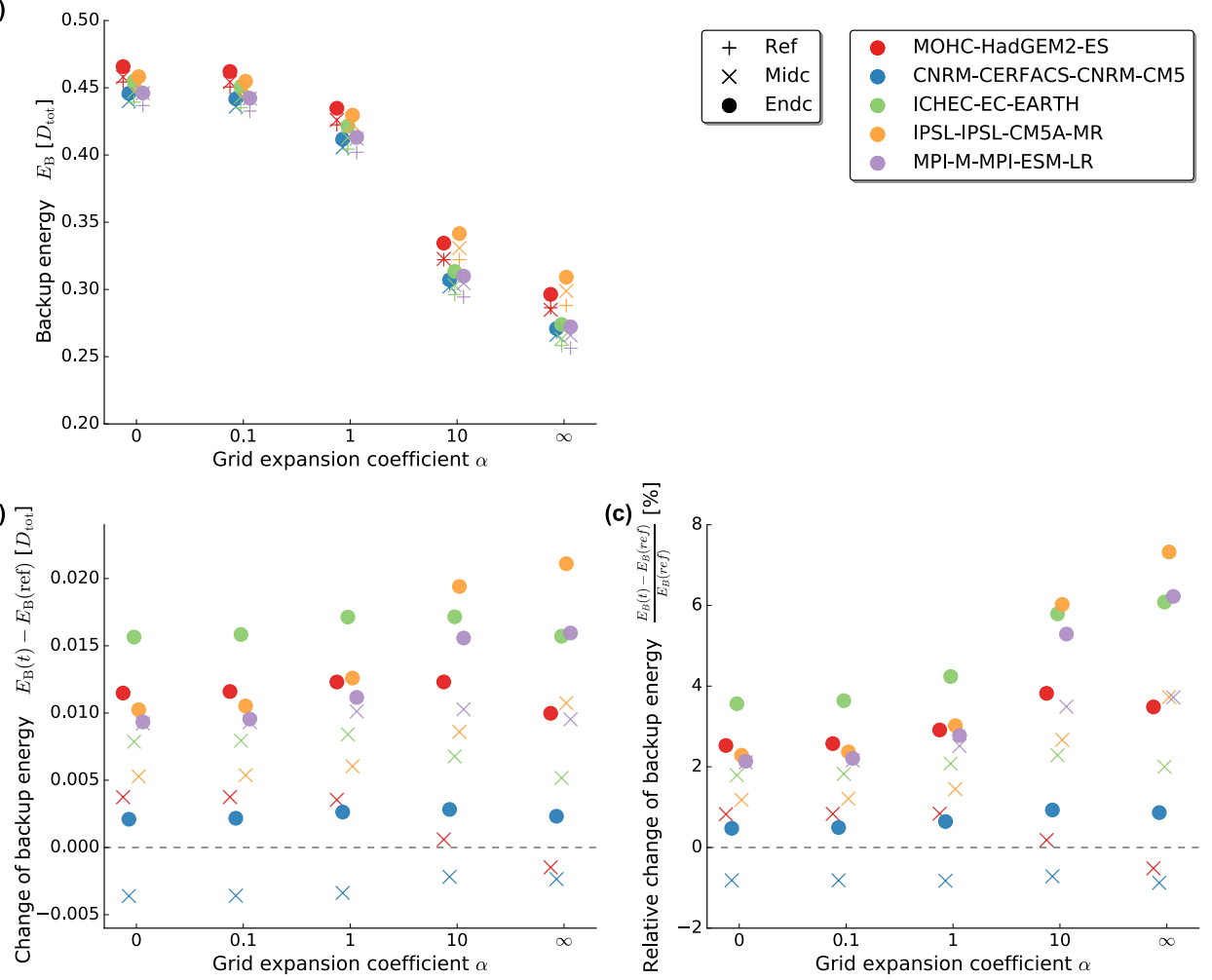

Figure 2. The impact of climate change on backup energy under different grid expansion scenarios. Different realizations of the European inter-state grid expansion are given by the grid expansion coefficient $\alpha$. While $\alpha=0$ denotes the isolated case without an inter-country transmission network, $\alpha=1$ reproduces the configuration as of today and $\alpha=\infty$ represents unlimited European transmission. Different markers refer to distinct 20-year time periods (see Table 1), and colors denote different climate models. (a) Backup energy as a function of grid expansion expressed in units of the total European load $D_{\text {tot }}=\int \sum_{i} D_{i}(t) \mathrm{d} t$. (b) Absolute change of backup energy by the end of the century. (c) Relative change of backup energy by the end of the century.

Table 1. Periods used in this study. The reference period ref ends before 2005 because GCMs in CMIP5 are driven by historic emissions only until this date and follow different representative concentration scenarios afterwards.

\begin{tabular}{lcl}
\hline Period name & $t_{\text {start }}$ & $t_{\text {end }}$ \\
\hline ref & 1985 & 2004 \\
midc & 2040 & 2059 \\
endc & 2080 & 2099 \\
\hline
\end{tabular}

\section{Results and discussion}

\subsection{Energy: increasing backup energy}

A cost-efficient way of power balancing is given by transnational imports and exports. Remarkably, we find that strong climate change impedes the potential of this balancing measure in most of Europe (see Fig. 2). We report that backup energy in Europe increases under strong climate change by the end of the century. This finding is robust across all EUROCORDEX ensemble members. Since we consider a scenario where $100 \%$ of electricity is generated from renewables on average, an increase in backup energy is accompanied by an increase in excess energy which has to be curtailed.

To uncover this effect we simulate backup energy for different scenarios of the development of the transnational grid quantified by the NTCs. We allow for a homogeneous scaling of transmission capacity by multiplying NTCs by a factor $\alpha$. Without any grid $(\alpha=0)$, approximately $45 \%$ of the windenergy is produced at the wrong time and thus has to be curtailed and backed up later on. Strong grid extension $(\alpha \gg 1)$ clearly reduces backup energy to about $27 \%$ (see Fig. 2a). However, all models report an increase in backup energy at the end of the century. The effect of climate change is almost independent of a grid extension: the absolute increase in backup energy until end of century is largely independent of the expansion coefficient $\alpha$ for three out of five models (see Fig. 2b). Hence, the relative increase in backup energy paradoxically becomes even more pronounced for a strongly interconnected Europe (see Fig. 2c). Highly connected systems can suffer from an increase in backup energy of up to $7 \%$. There is considerable inter-model spread regarding the 
magnitude of change which varies by up to 1 order of magnitude depending on the climate model (see Fig. 2b, $\alpha=\infty$ ). In particular, changes for CNRM are generally weak and HadGEM2 features only a slight overall increase with grid expansion. However, remarkably, all models agree on the sign of change at the end of the century such that we consider the direction of change very likely.

In conclusion, we find that the effectiveness of transnational balancing decreases due to climate change. This decrease is due to more homogeneous wind generation as we will show in the climate section of this paper. Moreover, a control simulation including PV generation from Pfenninger and Staffell (2016) yields similar results although the magnitude of change is reduced by roughly a factor of 2 and only four out of five models agree on the sign of change (see Supplement S2). Results are barely sensitive to changes in the load time series as an assessment using constant loads reveals (see Supplement S3).

\section{Spatial distribution of mismatch contributions}

To obtain a more detailed view, we evaluate transnational balancing potentials separately for each country. We calculate the likeliness that a given country has a local scarcity $\left(M_{i}<0\right)$ while Europe as a whole suffers from a lack of generation $\left(\sum_{i} M_{i}<0\right)$. This corresponds to events where a country would favor importing electricity but can not due to a continent-wide scarcity. These events require conventional backup even in the case of unlimited transmission infrastructure and thus give a lower bound for backup energy. The approach allows us to identify those countries which are most responsible for overall scarcity. Mathematically speaking, we restrict our analysis to time steps $T_{i}$ with local and Europe-wide scarcity:

$T_{i}=\left\{t:\left(\sum_{j} M_{j}(t)<0\right.\right.$ and $\left.\left.M_{i}(t)<0\right)\right\}$

The negative mismatch contribution occurrence $v_{i}$ corresponds to the joint probability of country $i$ and Europe experiencing generation shortfall at the same time:

$v_{i}=\frac{\sum_{t \in T_{i}}}{N_{T}}$

where $N_{T}$ is the number of time steps. We define the annual energy that is lacking (i.e., generation shortfall) in country $i$ during European scarcity as

$L_{i}=\frac{\sum_{t \in T_{i}}\left|M_{i}(t)\right|}{20 y}$,

where we chose the absolute value of $M_{i}$ for convenience of interpretation. $L_{i}$ is given in $\mathrm{TWh} \mathrm{yr}^{-1}$. A high value of $L_{i}$ characterizes a country which would favor importing a large quantity of energy during European scarcity, whereas a low value of $L_{i}$ indicates a country whose generation shortfall can often be balanced by imports. In order to compare values of $L_{i}$ with loads, we provide country values for $D_{i}$ in the Supplement S5. The European sum is $\sum_{i} D_{i} \approx 3100 \mathrm{TWh} \mathrm{yr}^{-1}$.

Values for $v$ and $L$ during the reference period are shown in Fig. 3a, b. Large consumers like Germany and France are also the dominant contributors to European scarcity in terms of missing energy (see Fig. 3a). The German contribution corresponds to approximately $8 \%$ of the European annual load of $3100 \mathrm{TWh}$. However, the role of these countries, for example, in comparison to eastern Europe or Benelux, is less pronounced if only the occurrence of negative mismatch events $v$ is considered (see Fig. 3b). The reason for their strong impact on $L$ is thus primarily rooted in the high absolute values of their mismatches rather than their frequency. Moreover, a large consumer also has a bigger influence on the Europe-wide mismatches which implies that the conditions in Eq. (5) are not independent. For example, the European mismatch can be negative because of an elevated German mismatch and in such a situation a high contribution to $L$ would be observed. Interestingly, there is considerable spread regarding $v$ in different countries (Fig. 3b). Greece and Norway contribute the least often to European scarcity (less than $40 \%$ ) while central Europe contributes around 50$60 \%$ of the time.

Next, we focus on changes until the end of the 21 st century:

$\Delta v_{i}=\left.v_{i}\right|_{\text {endc }}-\left.v_{i}\right|_{\text {ref }}$ and $\Delta L_{i}=\left.L_{i}\right|_{\text {endc }}-\left.L_{i}\right|_{\text {ref }}$.

In France, Benelux, Scandinavia, the UK, Ireland and most countries in central Europe the negative mismatch contribution occurrence $v$ and the respective negative energy contribution $L$ increase (see Fig. 3c, d). In these countries it becomes more likely that a Europe-wide scarcity coincides with a local scarcity and the amount of required backup energy increases. In turn, these countries can not alleviate the overall shortage by exporting excess generation. This points to a stronger homogeneity of wind power generation in central Europe which is discussed in more detail below. An increase in the occurrence $v$ can also be observed for eastern and southeastern Europe, excluding Greece, with high intermodel agreement (see Fig. 3d). However, these increases are weak in terms of energy contributions (see Fig. 3c).

An opposite trend is observed in Spain, where transnational balancing is facilitated as negative mismatch contributions $L$ become weaker (see Fig. 3c). At the same time, models generally disagree on the sign of change regarding $\Delta v$ (see Fig. 3d). Combined, this indicates weaker but not less frequent negative contributions of Spain. Moreover, Greece shows favorable changes for the European system in terms of energy contributions and occurrences with a high intermodel agreement (see Fig. 3c, d). This finding is particularly 

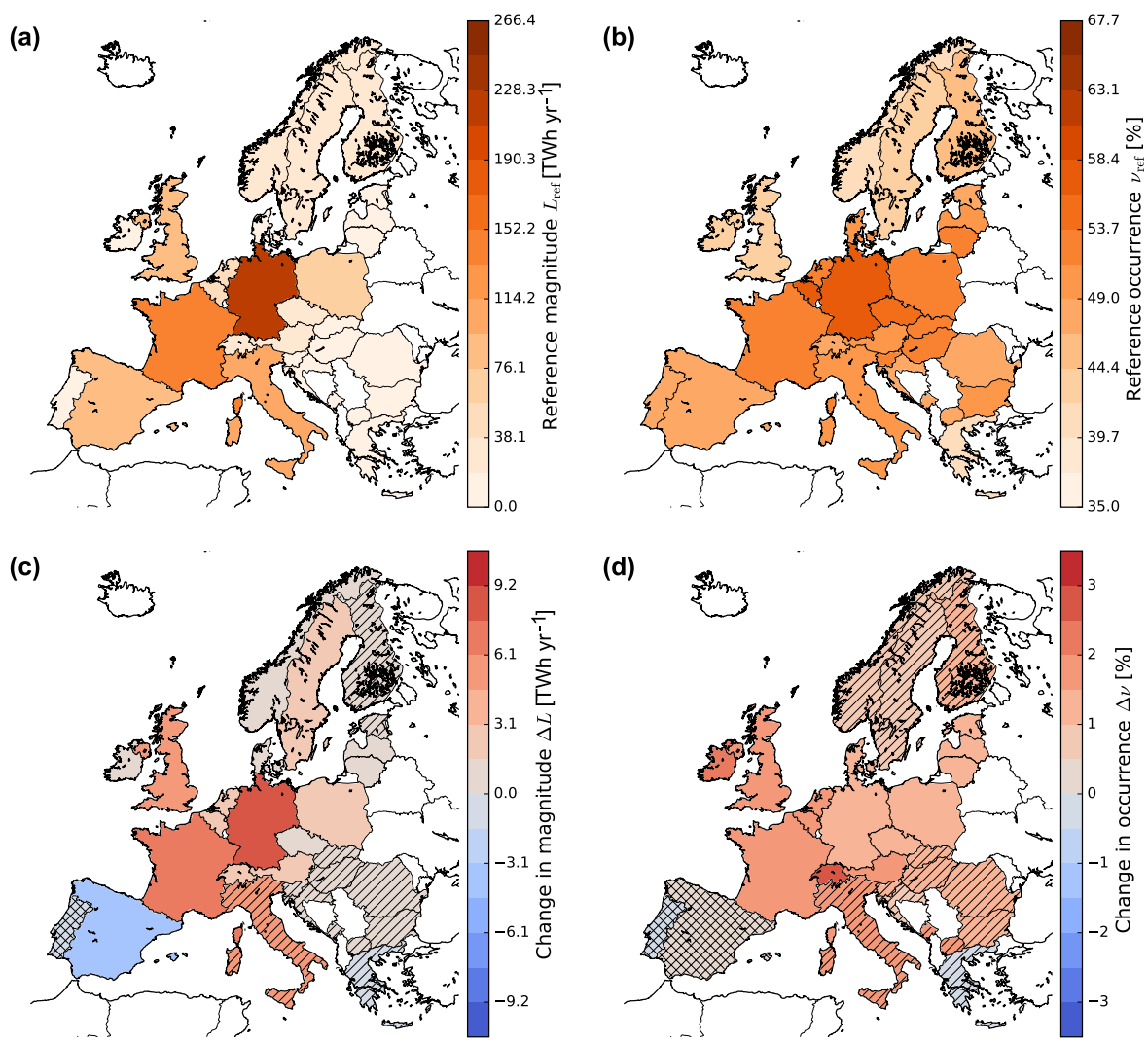

Figure 3. Country contributions in times of overall and local generation shortfall and their change until end of century. Values denote the inter-model mean. Shading indicates inter-model agreement as follows: no hatches indicate perfect agreement on sign of change; striped: four out of five models agree; hatching: less than four agree. (a) Lacking energy $L_{\text {ref }}$ during local and overall scarcity in the reference period (see Eq. 7). (b) Simultaneous occurrence of local and overall generation shortfall $v_{\text {ref }}$ (see Eq. 6). (c, d) Changes of the quantities given in (a, b) until end of century (see Eq. 8). Red colors denote unfavorable changes (stronger or more frequent contribution of a country to overall scarcity) while blue colors denote favorable changes.

interesting as Grams et al. (2017) show that a combination of wind parks allocated in the North Sea and the Balkans allows for substantial reduction in volatility under current climatic conditions. Based on our results, this positive effect from incorporating the Balkans would further be enhanced under strong climate change.

We stress that our findings do not refute the efficiency of transmission grid expansions in general. In any case backup energy decreases monotonously with the grid expansion, but the magnitude of the decrease is subject to climatic conditions. Furthermore, we assume a homogeneous expansion of the grid, although an optimal system design will probably lead to heterogeneous grid expansions and heterogeneous allocations of generation capacities. Our results suggest that such an optimal system will include stronger interconnections to Spain and Greece to reduce backup energy. Also, on a country level, certain extensions can be incentivized while others are downgraded. For instance, for France it can become more favorable to extend the connections to Spain rather than to Germany (see Fig. 3c). Despite this, and in light of regulatory and powerful social acceptance issues, regarding grid extensions (Battaglini et al., 2012), we consider a future grid which resembles the current one in its fundamental characteristics a reasonable first guess.

\subsection{Climate: increasing correlations of wind resources}

As reported above, we find an increase in backup energy due to strong climate change in a wind-powered electricity system. This increase is solely rooted in changes of wind resources since all other parameters are kept constant.

For the identification of changes in the spatial wind patterns, we perform a correlation analysis over 20 -year time spans of wind speeds (see Table 1). We use Pearson correlation on the highest spatial scale; i.e., we correlate every grid point to all others instead of aggregating the wind fields first. Hence, the full spatial detail of the downscaled climate data is taken into consideration. In order to visualize results, correlation values are averaged on country level in the next step. To highlight long-term trends, we only show correlation changes between 2080-2099 (endc) and 1985-2004 (ref): 
$\Delta R_{\text {endc }}(\mathrm{A}, \mathrm{B})=R_{\text {endc }}(\mathrm{A}, \mathrm{B})-R_{\text {ref }}(\mathrm{A}, \mathrm{B})$,

where $R_{\text {period }}(\mathrm{A}, \mathrm{B})$ denotes the average of all point-to-point correlations between country A and country B in a given period. The computation is repeated for all possible combinations $(\mathrm{A}, \mathrm{B})$. We calculate $\Delta R_{\text {endc }}(\mathrm{A}, \mathrm{B})$ for each climate model separately and show the model mean if not stated otherwise.

To reveal general patterns, we first consider the average correlation change of a fixed country A by averaging Eq. (9) over all countries B excluding A (see Fig. 4). There is a general tendency towards higher correlations of wind speeds for central Europe in the ensemble mean. This change is most pronounced in Germany, Switzerland, Benelux and Ireland. Decreasing correlations only occur at the fringes of the continent and they are strongest in Portugal and Greece. Positive correlation changes occur in most countries and the maximum positive change is approximately 3 times larger in magnitude than the maximum negative change. Interestingly, the overall pattern is similar to the mismatch contribution analysis (see Fig. 3). This similarity is not a trivial finding since the mismatch contribution analysis accounts for the nonlinear turbine power curve and the collective behavior of the entire electricity grid while the correlation analysis is solely based on wind speeds. Summarizing, we find more homogeneous wind conditions over most of the continent while the fringes decouple slightly. Results for mid-century are weaker but clearly similar (see Supplement Fig. S5).

Assessing pairwise correlation changes between countries, we find that the correlation increase over central Europe has at least a high agreement in the EURO-CORDEX ensemble (see Fig. 5). Some country combinations (e.g., DE-CZ, FRCZ, BE-UK, FR-NL) even show robust trends. For example, in Germany the correlations to all neighboring countries plus the UK, Ireland and eastern Europe increase with high agreement. The importance of this finding is strengthened by the fact that central Europe plays an important role for the power system: Germany, France, the United Kingdom, Poland and Benelux account for more than half of the European load. Correlations between Germany and Greece decrease with high model agreement. In contrast, changes between Germany and the Iberian Peninsula, Italy and Norway are uncertain.

The decoupling of Portugal and Greece which is found in the aggregated plot (Fig. 4) is only robust in a few country combinations and models disagree regarding some important pairs (e.g., PT-DE, PT-FR, PT-UK; GR-IT, GR-UK; and ES-FR, ES-DE). The uncertainty with respect to the correlation changes between these countries is thus high.

However, a robust trend is found in Scandinavia, where Norway, Finland and Sweden become more highly correlated. This change also partly holds for the Baltic region. At the same time Scandinavia decouples robustly from some

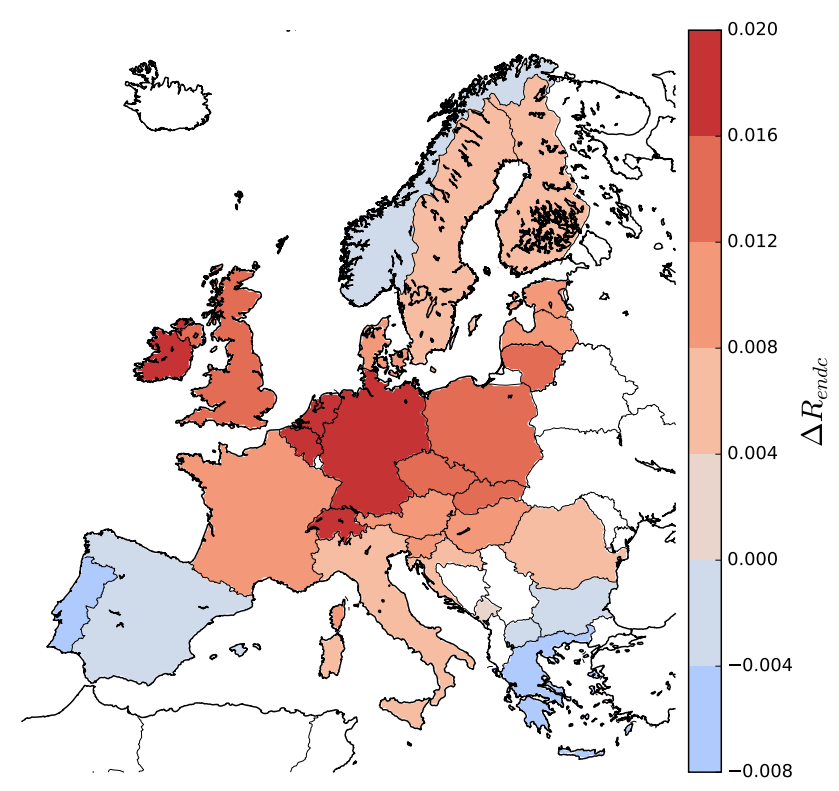

Figure 4. Correlation changes of wind time series averaged over all models (difference between end of century and reference correlations). A more detailed assessment, which in particular addresses inter-model spread, is shown in Fig. 5.

parts of southern Europe (e.g., SE-GR, NO-ES). In the context of large-scale European grid expansions, these alterations might enhance the value of high-voltage direct current (HVDC) lines between these distinct regions.

Correlation increases in Scandinavia are also robust in the middle of the century (see Supplement Fig. S6). However, inter-model agreement for correlation increases in central Europe is lower although the overall pattern is still conceivable. The decoupling of Portugal and Greece can be seen in the inter-model mean, while agreement across models is rare.

\subsection{Climate: complementing EURO-CORDEX with CMIP5 using circulation weather types}

The EURO-CORDEX data set includes only a five-member subset of all CMIP5 GCMs and might thus not be representative of the entire CMIP5 ensemble. Moreover, subgroups of GCMs can be biased in the same way since they did not develop separately, but along the same lines. The most drastic example is the sharing of code by CNRM and EC-EARTH, which are both part of the EURO-CORDEX ensemble and run the same atmosphere module (Knutti et al., 2013).

Uncertainty in climate projections has been argued to stem from three main sources: (1) natural variability, (2) model uncertainty and (3) scenario uncertainty (Hawkins and Sutton, 2009). In some situations the choice of initial conditions also contributes substantially (Hawkins et al., 2016). We neglect scenario uncertainty by design of this study since we only focus on the sensitivity to strong climate change (RCP8.5). As the importance of natural variability decreases with the time 

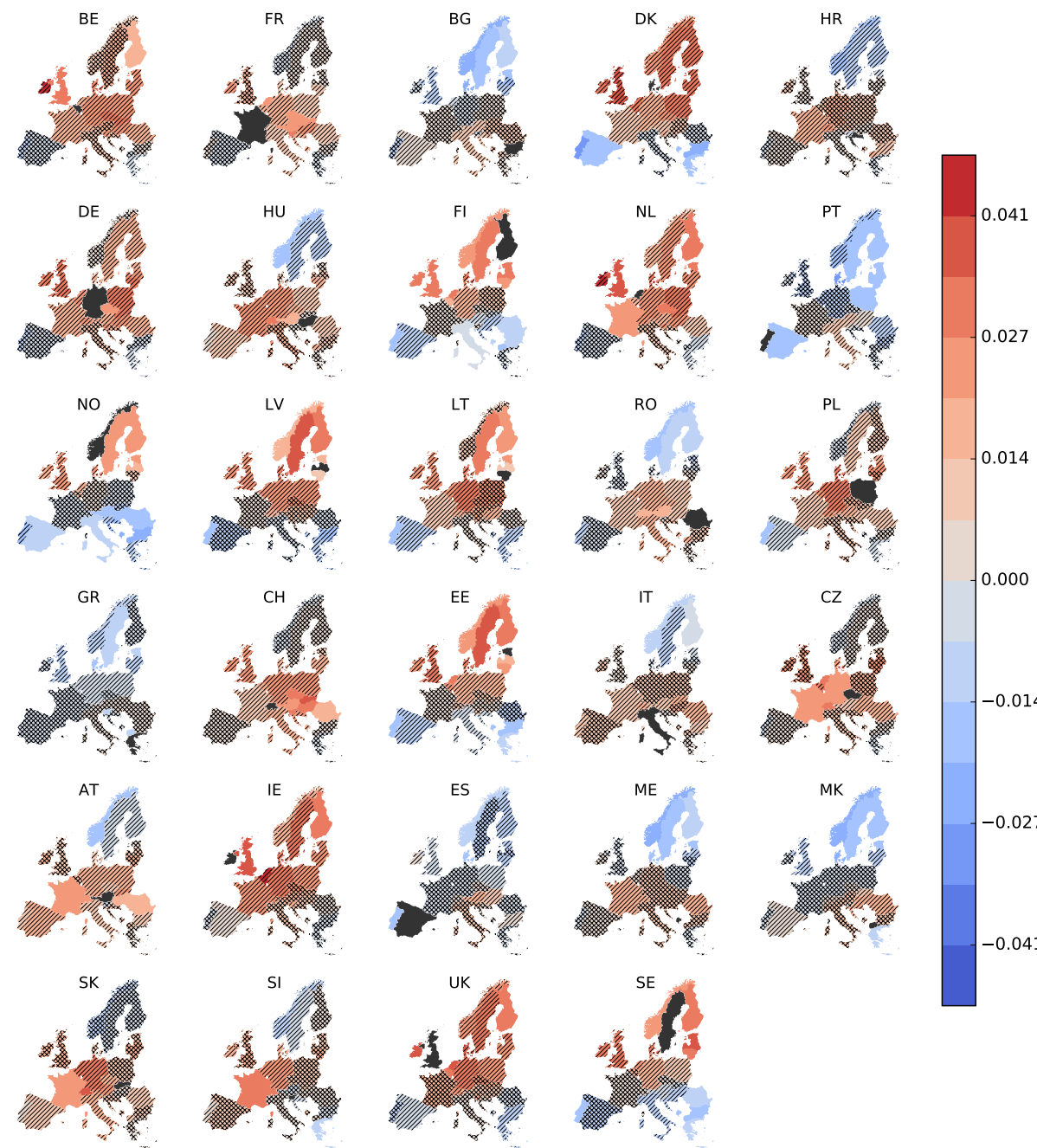

Figure 5. Country-specific change of wind speed correlations at the end of the 21st century including inter-model agreement. Colors denote the model-average correlation change of a country to the reference country (highlighted in black and given in the respective heading). Shading indicates inter-model agreement as follows: no hatches indicate perfect agreement on sign of change; striped: four out of five models agree; hatching: less than four agree.

intervals averaged over, model uncertainty is likely to be the dominant source of uncertainty here.

In order to rule out the possibility that our findings are biased due to the (arbitrary) choice of GCMs that were scaled down for EURO-CORDEX, we follow a statisticaldynamical approach which was developed by Reyers et al. $(2015,2016)$ to downscale a large CMIP5 ensemble for wind energy applications. This approach is based on a circulation weather type (CWT) classification methodology (Jones et al., 1993). Daily mean sea level pressure (MSLP) values at 16 GCM grid points around a central point located in Germany are used to assign the near-surface atmospheric flow over Europe to either a directional flow (north, northeast, east, etc.) or a rotational flow (anticyclonic, cyclonic). Aside from the direction of the atmospheric flow a $f$ parameter is calculated, which is representative of the instantaneous pressure gradient and thus for the general wind speed conditions over Germany and the surrounding countries:

$f=\sqrt{\mathrm{d} P_{z}^{2}+\mathrm{d} P_{m}^{2}}$,

where $\mathrm{d} P_{z}$ is the mean pressure gradient in east-west direction (zonal component) and $\mathrm{d} P_{m}$ is the mean pressure gradient in north-south direction (meridional component). $f$ parameter values from below $5 \mathrm{hPa}$ per $1000 \mathrm{~km}$ (weak MSLP gradient and thus low wind speed conditions) up to $45 \mathrm{hPa}$ per $1000 \mathrm{~km}$ (strong MSLP gradients and thus high wind speed conditions) were found. Reyers et al. (2016) demonstrated that such a CWT classification provides a suitable and effective basis for wind energy applications on the regional scale and therefore enables the consideration of a large CMIP5 ensemble in future projections. 

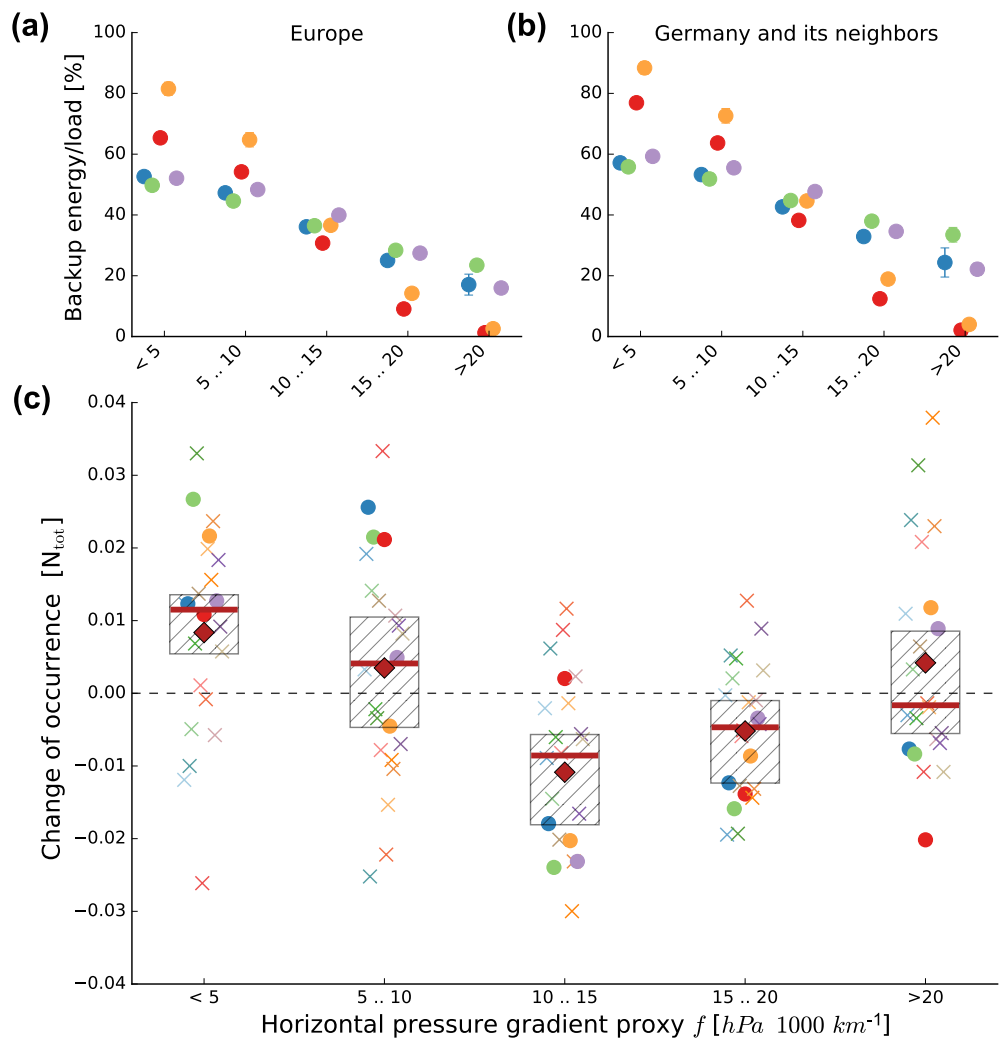

\begin{tabular}{|c|c|c|c|c|c|c|c|c|c|}
\hline$x$ & ACCESS1-3 & - & EC-EARTH & $x$ & HadGEM2-CC & $x$ & MIROC-ESM & $x$ & MPI-ESM-MR \\
\hline$x$ & CCSM4 & $x$ & FGOALS-g2 & - & HadGEM2-ES & $x$ & MIROC-ESMCH & $x$ & MRI-CGCM3 \\
\hline - & CNRM-CM5 & $x$ & GFDL-CM3 & $x$ & INM & $x$ & MIROC5 & $x$ & NorESM1-M \\
\hline$x$ & CSIRO & $x$ & GFDL-ESM2G & $x$ & IPSL-CM5ALR & ? & MPI-ESM-LR & 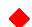 & Model-mean \\
\hline$x$ & Can & $x$ & GFDL-ESM2M & e & IPSL-CM5AMR & & & & \\
\hline
\end{tabular}

Figure 6. Backup energy and change of occurrence as a function of the $f$ parameter. (a) Backup energy versus $f$ parameter for the entire domain. Circles denote the mean over the three considered periods for each model and error bars indicate the standard deviation thereof. Error bars are, however, most often smaller than the circle size. (b) Same as (a) but restricted to Germany and its neighbors. (c) Change of occurrence of different $f$ parameter values. The change of occurrence is computed as the difference between end of century and the reference period and is given in units of the total number of time steps $N_{\text {tot }}$. Red diamonds denote the ensemble mean, red lines the ensemble median and hatched boxes indicate the 33rd to 67 th percentile. If a box lies completely above/below zero, the sign of the change can be considered as likely.

Analyzing the five individual GCMs contributing to the EURO-CORDEX ensemble reveals a link between the CWTs and the backup energy derived from dynamically downscaled data (see Eqs. 1, 2, 3). We find that backup energy decreases monotonously with increasing $f$ parameter values (see Fig. 6a, b). All models in the EURO-CORDEX ensemble agree on this result which is also physically plausible as the pressure gradient drives the atmospheric circulation. This statement holds for Germany and its neighbors and for Europe as a whole. We see this as evidence that the CWT analyses in this particular case can be applied to the entire continent in the sense that the $f$ parameter is a reasonable proxy for the European backup energy.

The majority of CMIP5 models (16 out of 22) predict an increase in events with low $f$ parameter values by the end of the century (see Fig. 6c). Following the likelihood classification developed for the latest IPCC report (Mastrandrea et al., 2010), it is thus likely that low $f$ parameter values become more abundant. This trend originates mainly from more frequent anticyclonic pressure configurations (see Fig. 7). For this CWT, spatial homogeneity of wind resources is higher as compared to all other CWTs (see Supplement Fig. S7). In such a homogeneous situation, it is plausible that backup energy is elevated since countries are more likely to experience shortfall of generation simultaneously. In contrast, medium $(10 \leq f[\mathrm{hPa} / 1000 \mathrm{~km}] \leq 15)$ and high $(15 \leq f[\mathrm{hPa} / 1000 \mathrm{~km}] \leq 20) f$ parameters are likely to occur less frequently since 17 models agree on these signals. We thus conclude that the majority of CMIP5 models agree with the main finding of increasing backup energy.

The larger CMIP5 ensemble also allows for an assessment of the EURO-CORDEX ensemble input data. We re- 


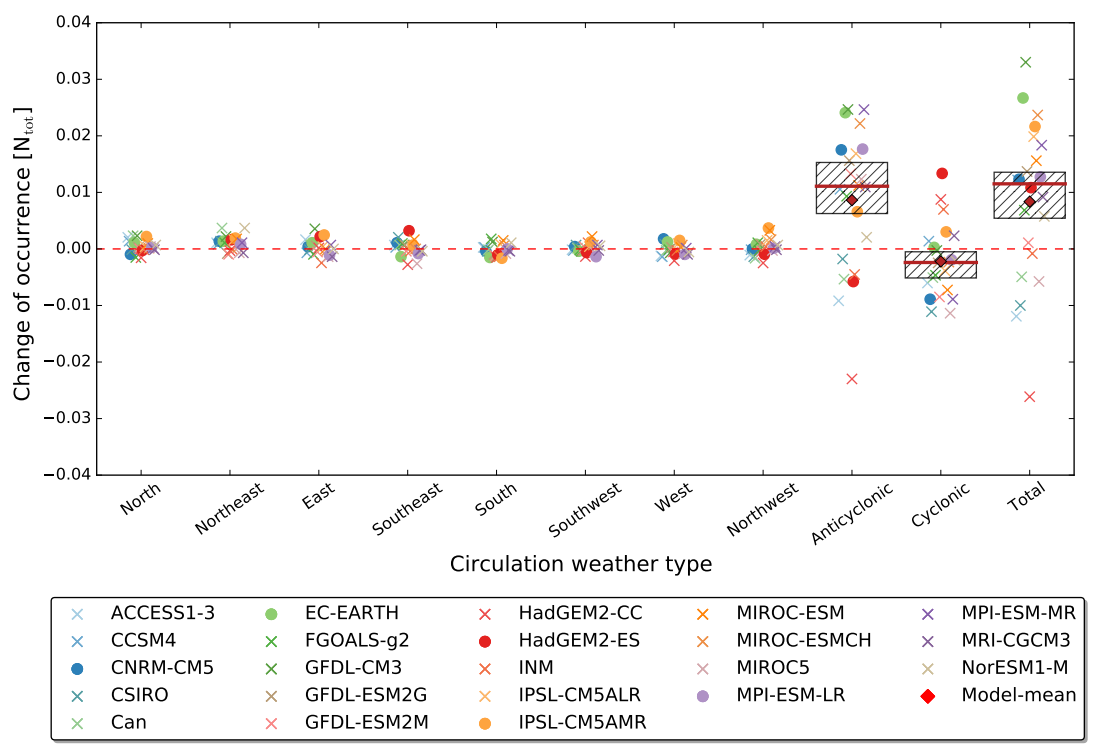

Figure 7. Changes of relative occurrence of primary CWTs with low $f$ parameter values $(f \leq 5 \mathrm{hPa} / 1000 \mathrm{~km})$. Changes are differences in occurrence between end of century and the reference period and are given in units of the total number of time steps $N_{\text {tot }}$. Boxes indicate the 33 rd to 67 th percentile and are only shown if changes are substantial. Red diamonds denote the ensemble mean and red lines denote the ensemble median.

port that the GCMs contributing to EURO-CORDEX are within the spread of the remaining CMIP5 ensemble (except for HadGEM with very strong $f$ parameters) and are thus generally representative of the larger ensemble (see Fig. 6). However, they also show comparably strong changes in the occurrence of specific $f$ parameters. The CMIP5 overall projection regarding backup energy might thus be lower than results reported in this paper. In order to test this speculative hypothesis, a consistent downscaling of all CMIP5 models would be necessary, which is far beyond the scope of this article but should be tackled in future works.

\section{Conclusions}

A future highly renewable electricity system will be governed by weather conditions. If mankind fails to reduce carbon emissions fast, climate change will impede the operation of a wind-driven system in Europe. This conclusion is based on three separate lines of evidence.

1. A coarse-scale electricity model fed with EUROCORDEX climate data shows robust increases in backup energy.

2. Spatial correlations in wind time series in EUROCORDEX data across central Europe are found to increase. Countries are thus more likely to experience generation shortfall simultaneously.

3. Building upon a statistical-dynamical downscaling technique and a 22-member CMIP5 ensemble we find a likely increase in circulation weather types with low $f$ parameters values. They are associated with low Europe-wide wind generation.

It has to be stressed that results are for the end of the 21st century and based on a strong climate change scenario (RCP8.5). They should be thought of as a sensitivity test. While the increases of backup energy are robust, they are also restricted to relative increases of $7 \%$ (see Fig. 2). A fully renewable electricity system will hence not become unfeasible due to catastrophic changes.

In the emerging field of linking energy and climate research, many additional questions are to be addressed in order to deliver a more holistic assessment. We simulated a wind-driven electricity system and performed a control simulation with a fixed share of PV. Time series for the latter were taken from a validated data set based on reanalysis data (Pfenninger and Staffell, 2016). Ideally, future works would assess the combined effects of climate change on wind and solar generation. They could also include concentrated solar power since this technology bears advantages for system integration (Pfenninger et al., 2014). Load shifting, sector coupling and storage are further topics for more detailed assessments.

In terms of climate modeling output, a larger highresolution ensemble which contains multiple regional climate models (RCMs) is particularly desirable. The next generation of CORDEX is planned to deliver such data (Gutowski Jr. et al., 2016) and will hence allow for an inclusion of RCM spread in future assessments. It will also facilitate similar assessment for other world regions as spatial extent is expanded. 
Data availability. The climate data (EUROCORDEX and CMIP5) are accessible via the ESGF: https://esgf-data.dkrz. de/search/cordex-dkrz/. Hourly load data are provided by the European Network of Transmission System Operators for Electricity at https://www.entsoe.eu/db-query/consumption/ mhlv-all-countries-for-a-specific-month. The current net transfer capacities for Europe are made available by the same body at https://www.entsoe.eu/fileadmin/user_upload/_library/ntc/archive/ NTC-Values-Winter-2010-2011.pdf.

\section{The Supplement related to this article is available online at https://doi.org/10.5194/esd-8-1047-2017-supplement.}

Author contributions. JaW performed the simulations, analyzed the data, produced all figures and wrote most of the manuscript. DW conceived and supervised the research and contributed to the writing, in particular regarding the electricity system. MR supplied the CWT analysis and wrote parts of the CWT chapter. All authors contributed ideas, gave feedback and helped to improve the manuscript.

Competing interests. The authors declare that they have no conflict of interest.

Acknowledgements. We thank Martin Greiner, Gorm Bruun Andresen, Smail Kozarcanin, Tom Brown, David Schlachtberger and Christoph Ball for stimulating discussions. We owe Julia Brugger gratitude for checking the final manuscript. We also acknowledge the World Climate Research Programme's Working Group on Regional Climate, and the Working Group on Coupled Modeling, former coordinating body of CORDEX and responsible panel for CMIP5. We thank the climate modeling groups for producing and making available their model output. We acknowledge the Earth System Grid Federation infrastructure an international effort led by the U.S. Department of Energy's Program for Climate Model Diagnosis and Intercomparison, the European Network for Earth System Modelling and other partners in the Global Organization for Earth System Science Portals (GO-ESSP). The authors gratefully acknowledge the computing time granted by the JARA-HPC Vergabegremium on the supercomputer JURECA (Jülich Supercomputing Centre, 2016) at Forschungszentrum Jülich. We gratefully acknowledge support from the Helmholtz Association (via the joint initiative "Energy System 2050 - A Contribution of the Research Field Energy" and the grant no. VH-NG-1025 to Dirk Witthaut).

The article processing charges for this open-access publication were covered by a Research

Centre of the Helmholtz Association.

Edited by: Somnath Baidya Roy

Reviewed by: two anonymous referees

\section{References}

Anderson, K. and Peters, G.: The trouble with negative emissions, Science, 354, 182-183, 2016.

Auffhammer, M., Baylis, P., and Hausman, C. H.: Climate change is projected to have severe impacts on the frequency and intensity of peak electricity demand across the United States, P. Natl. Acad. Sci. USA, 114, 1886-1891, https://doi.org/10.1073/pnas.1613193114, 2017.

Battaglini, A., Komendantova, N., Brtnik, P., and Patt, A.: Perception of barriers for expansion of electricity grids in the European Union, Energy Policy, 47, 254-259, https://doi.org/10.1016/j.enpol.2012.04.065, 2012.

Becker, S., Rodriguez, R., Andresen, G., Schramm, S., and Greiner, M.: Transmission grid extensions during the build-up of a fully renewable pan-European electricity supply, Energy, 64, 404-418, https://doi.org/10.1016/j.energy.2013.10.010, 2014.

Bloomfield, H. C., Brayshaw, D. J., Shaffrey, L. C., Coker, P. J., and Thornton, H. E.: Quantifying the increasing sensitivity of power systems to climate variability, Environ. Res. Lett., 11, 124025, https://doi.org/10.1088/1748-9326/11/12/124025, 2016.

Brown, T., Schierhorn, P.-P., Troester, E., and Ackermann, T.: Optimising the European transmission system for $77 \%$ renewable electricity by 2030, IET Renew. Power Gen., 10, 3-9, https://doi.org/10.1049/iet-rpg.2015.0135, 2016.

Bruckner, T., Bashmakov, I. A., Mulugetta, Y., Chum, H., de la Vega Navarro, A., Edmonds, J., Faaij, A., Fungtammasan, B., Garg, A., Hertwich, E., Honnery, D., Infield, D., Kainuma, M., Khennas, S., Kim, S., Nimir, H. B., Riahi, K., Strachan, N., Wiser, R., and Zhang, X.: Energy Systems, in: Climate Change 2014: Mitigation of Climate Change. Contribution of Working Group III to the Fifth Assessment Report of the Intergovernmental Panel on Climate Change, edited by: Edenhofer, O., Pichs-Madruga, R., Sokona, Y., Farahani, E., Kadner, S., Seyboth, K., Adler, A., Baum, I., Brunner, S., Eickemeier, P., Kriemann, B., Savolainen, J., Schlömer, S., von Stechow, C., Zwickel, T., and Minx, J. C., Cambridge University Press, Cambridge, UK and New York, NY, USA, 2014.

Chiacchio, M., Solmon, F., Giorgi, F., Stackhouse, P., and Wild, M.: Evaluation of the radiation budget with a regional climate model over Europe and inspection of dimming and brightening: Evaluation of the radiation budget, J. Geophys. Res.-Atmos., 120, 1951-1971, https://doi.org/10.1002/2014JD022497, 2015.

Coumou, D., Lehmann, J., and Beckmann, J.: The weakening summer circulation in the Northern Hemisphere mid-latitudes, Science, 348, 324-327, 2015.

Crook, J. A., Jones, L. A., Forster, P. M., and Crook, R.: Climate change impacts on future photovoltaic and concentrated solar power energy output, Energ. Environ. Sci., 4, 3101, https://doi.org/10.1039/c1ee01495a, 2011.

Davis, S. J., Caldeira, K., and Matthews, H. D.: Future $\mathrm{CO}_{2}$ Emissions and Climate Change from Existing Energy Infrastructure, Science, 329, 1330-1333, https://doi.org/10.1126/science.1194210, 2010.

Ely, C. R., Brayshaw, D. J., Methven, J., Cox, J., and Pearce, O.: Implications of the North Atlantic Oscillation for a UKNorway Renewable power system, Energ. Policy, 62, 14201427, https://doi.org/10.1016/j.enpol.2013.06.037, 2013. 
European Network of Transmission System Operators for Electricity: Hourly load values for all countries for a specific month (in MW), available at: https://www.entsoe.eu/db-query/ consumption/mhlv-all-countries-for-a-specific-month (last access: 21 November 2016), 2015.

Farneti, R.: Modelling interdecadal climate variability and the role of the ocean, Wiley Interdisciplinary Reviews: Climate Change, 8, e441, https://doi.org/10.1002/wcc.441, 2017.

Gonzalez Aparcio, I., Zucker, A., Careri, F., Monforti, F., Huld, T., and Badger, J.: EMHIRES dataset; Part 1: Wind power generation, Tech. Rep. EUR 28171 EN, Joint Research Center, 2016.

Grams, C. M., Beerli, R., Pfenninger, S., Staffell, I., and Wernli, H.: Balancing Europe's wind-power output through spatial deployment informed by weather regimes, Nature Climate Change, 7 , 557-562, https://doi.org/10.1038/nclimate3338, 2017.

Gutowski Jr., W. J., Giorgi, F., Timbal, B., Frigon, A., Jacob, D., Kang, H.-S., Raghavan, K., Lee, B., Lennard, C., Nikulin, G., O'Rourke, E., Rixen, M., Solman, S., Stephenson, T., and Tangang, F.: WCRP COordinated Regional Downscaling EXperiment (CORDEX): a diagnostic MIP for CMIP6, Geosci. Model Dev., 9, 4087-4095, https://doi.org/10.5194/gmd-9-4087-2016, 2016.

Haarsma, R. J., Selten, F., and van Oldenborgh, G. J.: Anthropogenic changes of the thermal and zonal flow structure over Western Europe and Eastern North Atlantic in CMIP3 and CMIP5 models, Clim. Dynam., 41, 2577-2588, https://doi.org/10.1007/s00382-013-1734-8, 2013.

Haekkinen, S., Rhines, P. B., and Worthen, D. L.: Atmospheric Blocking and Atlantic Multidecadal Ocean Variability, Science, 334, 655-659, 2011.

Hagspiel, S., Jaegemann, C., Lindenberger, D., Brown, T., Cherevatskiy, S., and Troester, E.: Cost-optimal power system extension under flow-based market coupling, Energy, 66, 654-666, https://doi.org/10.1016/j.energy.2014.01.025, 2014.

Hawkins, E. and Sutton, R.: The potential to narrow uncertainty in regional climate predictions, B. Am. Meteorol. Soc., 90, 10951107, https://doi.org/10.1175/2009BAMS2607.1, 2009.

Hawkins, E., Smith, R. S., Gregory, J. M., and Stainforth, D. A.: Irreducible uncertainty in near-term climate projections, Clim. Dynam., 46, 3807-3819, https://doi.org/10.1007/s00382-015-2806$8,2016$.

Herwehe, J. A., Alapaty, K., Spero, T. L., and Nolte, C. G.: Increasing the credibility of regional climate simulations by introducing subgrid-scale cloud-radiation interactions, J. Geophys. Res.-Atmos., 119, 5317-5330, https://doi.org/10.1002/2014JD021504, 2014.

Huber, M., Dimkova, D., and Hamacher, T.: Integration of wind and solar power in Europe: Assessment of flexibility requirements, Energy, 69, 236-246, https://doi.org/10.1016/j.energy.2014.02.109, 2014.

Jacob, D., Petersen, J., Eggert, B., Alias, A., Christensen, O. B., Bouwer, L. M., Braun, A., Colette, A., Déqué, M., Georgievski, G., Georgopoulou, E., Gobiet, A., Menut, L., Nikulin, G., Haensler, A., Hempelmann, N., Jones, C., Keuler, K., Kovats, S., Kröner, N., Kotlarski, S., Kriegsmann, A., Martin, E., van Meijgaard, E., Moseley, C., Pfeifer, S., Preuschmann, S., Radermacher, C., Radtke, K., Rechid, D., Rounsevell, M., Samuelsson, P., Somot, S., Soussana, J.-F., Teichmann, C., Valentini, R., Vautard, R., Weber, B., and Yiou, P.: EURO-
CORDEX: new high-resolution climate change projections for European impact research, Reg. Environ. Change, 14, 563-578, https://doi.org/10.1007/s10113-013-0499-2, 2014.

James, R., Washington, R., Schleussner, C.-F., Rogelj, J., and Conway, D.: Characterizing half-a-degree difference: a review of methods for identifying regional climate responses to global warming targets: Characterizing half-a-degree difference, Wiley Interdisciplinary Reviews: Climate Change, 8, e457, https://doi.org/10.1002/wcc.457, 2017.

Jerez, S., Tobin, I., Vautard, R., Montávez, J. P., López-Romero, J. M., Thais, F., Bartok, B., Christensen, O. B., Colette, A., Déqué, M., Nikulin, G., Kotlarski, S., van Meijgaard, E., Teichmann, C., and Wild, M.: The impact of climate change on photovoltaic power generation in Europe, Nat. Commun., 6, 10014, https://doi.org/10.1038/ncomms10014, 2015.

Jones, P. D., Hulme, M., and Briffa, K. R.: A comparison of Lamb circulation types with an objective classification scheme, Int. J. Climatol., 13, 655-663, 1993.

Jülich Supercomputing Centre: JURECA: General-purpose supercomputer at Jülich Supercomputing Centre, Journal of LargeScale Research Facilities, 2, A62, https://doi.org/10.17815/jlsrf2-121, 2016.

Knutti, R., Masson, D., and Gettelman, A.: Climate model genealogy: Generation CMIP5 and how we got there, Geophys. Res. Lett., 40, 1194-1199, https://doi.org/10.1002/grl.50256, 2013.

Mastrandrea, M. D., Field, C. B., Stocker, T. F., Edenhofer, O., Ebi, K. L., Frame, D. J., Held, H., Kriegler, E., Mach, K. J., Matschoss, P. R., Plattner, G.-K., Yohe, G. W., and Zwiers, F. W.: Guidance note for lead authors of the IPCC fifth assessment report on consistent treatment of uncertainties, available at: http://pubman.mpdl.mpg.de/pubman/item/escidoc:2147184/ component/escidoc:2147185/uncertainty-guidance-note.pdf (last access: 13 April 2017), 2010.

Moemken, J., Reyers, M., Buldmann, B., and Pinto, J. G.: Decadal predictability of regional scale wind speed and wind energy potentials over Central Europe, Tellus A, 68, 29199, https://doi.org/10.3402/tellusa.v68.29199, 2016.

Monforti, F., Gaetani, M., and Vignati, E.: How synchronous is wind energy production among European countries?, Renewable and Sustainable Energy Reviews, 59, 1622-1638, https://doi.org/10.1016/j.rser.2015.12.318, 2016.

Peings, Y. and Magnusdottir, G.: Forcing of the wintertime atmospheric circulation by the multidecadal fluctuations of the North Atlantic ocean, Environ. Res. Lett., 9, 034018, https://doi.org/10.1088/1748-9326/9/3/034018, 2014.

Pfenninger, S. and Staffell, I.: Long-term patterns of European PV output using 30 years of validated hourly reanalysis and satellite data, Energy, 114, 1251-1265, https://doi.org/10.1016/j.energy.2016.08.060, 2016.

Pfenninger, S., Gauché, P., Lilliestam, J., Damerau, K., Wagner, F., and Patt, A.: Potential for concentrating solar power to provide baseload and dispatchable power, Nature Climate Change, 4, 689-692, https://doi.org/10.1038/nclimate2276, 2014.

Rasmussen, M. G., Andresen, G. B., and Greiner, M.: Storage and balancing synergies in a fully or highly renewable pan-European power system, Energy Policy, 51, 642-651, https://doi.org/10.1016/j.enpol.2012.09.009, 2012.

Reyers, M., Pinto, J. G., and Moemken, J.: Statistical-dynamical downscaling for wind energy potentials: evaluation and applica- 
tions to decadal hindcasts and climate change projections, Int. J. Climatol., 35, 229-244, https://doi.org/10.1002/joc.3975, 2015.

Reyers, M., Moemken, J., and Pinto, J. G.: Future changes of wind energy potentials over Europe in a large CMIP5 multi-model ensemble, Int. J. Climatol., 36, 783-796, https://doi.org/10.1002/joc.4382, 2016.

Rodriguez, R. A., Becker, S., Andresen, G. B., Heide, D., and Greiner, M.: Transmission needs across a fully renewable European power system, Renew. Energ., 63, 467-476, https://doi.org/10.1016/j.renene.2013.10.005, 2014.

Rodriguez, R. A., Becker, S., and Greiner, M.: Costoptimal design of a simplified, highly renewable panEuropean electricity system, Energy, 83, 658-668, https://doi.org/10.1016/j.energy.2015.02.066, 2015a.

Rodriguez, R. A., Dahl, M., Becker, S., and Greiner, M.: Localized vs. synchronized exports across a highly renewable panEuropean transmission network, Energy, Sustainability and Society, 5, 21, https://doi.org/10.1186/s13705-015-0048-6, 2015b.

Rogelj, J., Luderer, G., Pietzcker, R. C., Kriegler, E., Schaeffer, M., Krey, V., and Riahi, K.: Energy system transformations for limiting end-of-century warming to below $1.5^{\circ} \mathrm{C}$, Nature Climate Change, 5, 519-527, https://doi.org/10.1038/nclimate2572, 2015.

Rogelj, J., den Elzen, M., Hoehne, N., Fransen, T., Fekete, H., Winkler, H., Schaeffer, R., Sha, F., Riahi, K., and Meinshausen, M.: Paris Agreement climate proposals need a boost to keep warming well below $2{ }^{\circ} \mathrm{C}$, Nature, 534, 631-639, https://doi.org/10.1038/nature18307, 2016.

Rummukainen, M.: Added value in regional climate modeling, Wiley Interdisciplinary Reviews: Climate Change, 7, 145-159, https://doi.org/10.1002/wcc.378, 2016.

Schlachtberger, D., Becker, S., Schramm, S., and Greiner, M.: Backup flexibility classes in emerging large-scale renewable electricity systems, Energ. Convers. Manage., 125, 336-346, https://doi.org/10.1016/j.enconman.2016.04.020, 2016.

Schlachtberger, D., Brown, T., Schramm, S., and Greiner, M.: The benefits of cooperation in a highly renewable European electricity network, Energy, 134, 469-481, https://doi.org/10.1016/j.energy.2017.06.004, 2017.

Schleussner, C.-F., Lissner, T. K., Fischer, E. M., Wohland, J., Perrette, M., Golly, A., Rogelj, J., Childers, K., Schewe, J., Frieler, K., Mengel, M., Hare, W., and Schaeffer, M.: Differential climate impacts for policy-relevant limits to global warming: the case of $1.5^{\circ} \mathrm{C}$ and $2{ }^{\circ} \mathrm{C}$, Earth Syst. Dynam., 7, 327-351, https://doi.org/10.5194/esd-7-327-2016, 2016a.

Schleussner, C.-F., Rogelj, J., Schaeffer, M., Lissner, T., Licker, R., Fischer, E. M., Knutti, R., Levermann, A., Frieler, K., and Hare, W.: Science and policy characteristics of the Paris Agreement temperature goal, Nature Climate Change, 6, 827-835, https://doi.org/10.1038/nclimate3096, 2016b.

Staffell, I. and Pfenninger, S.: Using bias-corrected reanalysis to simulate current and future wind power output, Energy, 114, 1224-1239, https://doi.org/10.1016/j.energy.2016.08.068, 2016.

Stocker, T. F., Qin, D., Plattner, G.-K., et al.: Technical summary, in: Climate Change 2013: The Physical Science Basis. Contribution of Working Group I to the Fifth Assessment Report of the Intergovernmental Panel on Climate Change, 33-115, Cambridge University Press, available at: http://pubman.mpdl.mpg.de/pubman/item/escidoc:1977530/
component/escidoc:1977527/WG1AR5_TS_FINAL.pdf (last access: 3 March 2017), 2013.

Strandberg, G., Bärring, L., Hansson, U., Jansson, C., Jones, C., Kjellström, E., Kolax, M., Kupiainen, M., Nikulin, G., Samuelsson, P., Ullerstig, A., and Wang, S.: CORDEX scenarios for Europe from the Rossby Centre regional climate model RCA4, SMHI, Sveriges Meteorologiska och Hydrologiska Institut, 2015.

Taylor, K. E., Stouffer, R. J., and Meehl, G. A.: An Overview of CMIP5 and the Experiment Design, B. Am. Meteorol. Soc., 93, 485-498, 2011.

Tobin, I., Vautard, R., Balog, I., Bréon, F.-M., Jerez, S., Ruti, P. M., Thais, F., Vrac, M., and Yiou, P.: Assessing climate change impacts on European wind energy from ENSEMBLES highresolution climate projections, Climatic Change, 128, 99-112, https://doi.org/10.1007/s10584-014-1291-0, 2015.

Tobin, I., Jerez, S., Vautard, R., Thais, F., van Meijgaard, E., Prein, A., Deque, M., Kotlarski, S., Maule, C. F., Nikulin, G., Noel, T., and Teichmann, C.: Climate change impacts on the power generation potential of a European mid-century wind farms scenario, Environ. Res. Lett., 11, 034013, https://doi.org/10.1088/17489326/11/3/034013, 2016.

Trump, D. J.: Presidential Executive Order on Promoting Energy Independence and Economic Growth, available at: https://www.whitehouse.gov/the-pressoffice/2017/03/28/presidential-executive-order-promotingenergy-independence-and-economi-1 (last access: 4 June 2017), 2017.

UNFCCC: Adoption of the Paris Agreement, FCCC/CP/2015/10/Add.1, 2015.

van Vliet, M. T. H., Yearsley, J. R., Ludwig, F., Voegele, S., Lettenmaier, D. P., and Kabat, P.: Vulnerability of US and European electricity supply to climate change, Nature Climate Change, 2, 676-681, https://doi.org/10.1038/nclimate1546, 2012.

van Vliet, M. T. H., Wiberg, D., Leduc, S., and Riahi, K.: Powergeneration system vulnerability and adaptation to changes in climate and water resources, Nature Climate Change, 6, 375-380, https://doi.org/10.1038/nclimate2903, 2016.

van Vuuren, D. P., van Soest, H., Riahi, K., Clarke, L., Krey, V., Kriegler, E., Rogelj, J., Schaeffer, M., and Tavoni, M.: Carbon budgets and energy transition pathways, Environ. Res. Lett., 11, 075002, https://doi.org/10.1088/1748-9326/11/7/075002, 2016.

Vautard, R., Thais, F., Tobin, I., Bréon, F.-M., de Lavergne, J.G. D., Colette, A., Yiou, P., and Ruti, P. M.: Regional climate model simulations indicate limited climatic impacts by operational and planned European wind farms, Nat. Commun., 5, 3196, https://doi.org/10.1038/ncomms4196, 2014.

Weber, J., Wohland, J., Reyers, M., Moemken, J., Hoppe, C., Pinto, J. G., and Witthaut, D.: Impact of climate change on backup and storage needs in a wind-dominated European power system, in review, 2017.

Wiser, R., Bolinger, M., Barbose, G., Darghouth, N., Hoen, B., Mills, A., Rand, J., Millstein, D., Porter, K., and Widiss, R.: 2015 Wind Technologies Market Report, available at: https://pubarchive.lbl.gov/islandora/object/ir\%3A1005951/ data\%stream/PDF/download/citation.pdf (last access: 28 August 2017), 2016. 